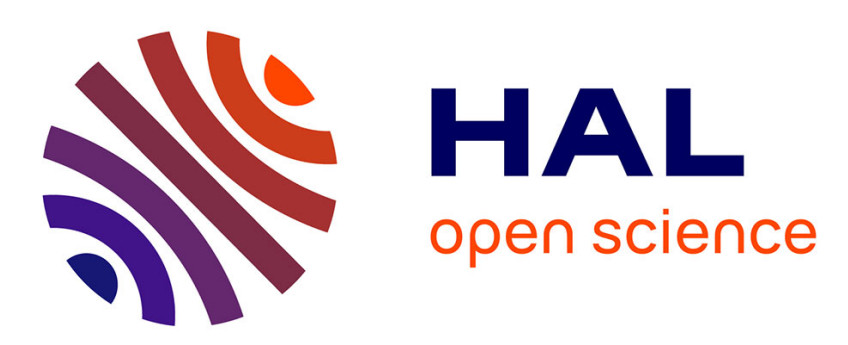

\title{
Managing expert-information uncertainties for assessing collapse susceptibility of abandoned underground structures
}

\author{
Aude Nachbaur, Jeremy Rohmer
}

\section{- To cite this version:}

Aude Nachbaur, Jeremy Rohmer. Managing expert-information uncertainties for assessing collapse susceptibility of abandoned underground structures. Engineering Geology, 2011, 123, pp.166-178. 10.1016/j.enggeo.2011.07.007 . hal-00657797

\section{HAL Id: hal-00657797 https: / hal-brgm.archives-ouvertes.fr/hal-00657797}

Submitted on 9 Jan 2012

HAL is a multi-disciplinary open access archive for the deposit and dissemination of scientific research documents, whether they are published or not. The documents may come from teaching and research institutions in France or abroad, or from public or private research centers.
L'archive ouverte pluridisciplinaire HAL, est destinée au dépôt et à la diffusion de documents scientifiques de niveau recherche, publiés ou non, émanant des établissements d'enseignement et de recherche français ou étrangers, des laboratoires publics ou privés. 


\title{
Managing expert-information uncertainties for assessing collapse susceptibility of abandoned underground structures
}

\author{
Nachbaur Aude ${ }^{1 *}$, Rohmer Jérémy $^{1}$ \\ ${ }^{1}$ BRGM, 3 avenue C. Guillemin 45060 Orleans Cedex 2 France \\ *Corresponding author: e-mail: a.nachbaur@brgm.fr, Tel.: +332 38643965
}

\begin{abstract}
Assessing the collapse susceptibility of abandoned cavities at a regional scale is associated with large uncertainties that are mainly related to the very nature of the phenomena, but also to the difficulty in collecting exhaustive information at such a scale on often "forgotten" structures. In this context, the expert's role is essential, because he is able to synthesize the information resulting from the inventory and from the commonly imprecise, if not vague, criteria on the basis of his experience and his knowledge of the regional geological and historical and economic context.

In this article, we propose mathematical tools for representing and processing this information in order to give flexibility to this step and manage the uncertainty inherent in the expert's information. The first tool, based on the weight of evidence theory, is for managing the uncertainty due to the heterogeneous spatial distribution of the data, whereas the second tool, based on the fuzzy set theory, is for managing the imprecision and incompleteness of available data, which hinder the definition of the class boundaries of the quantitative decision criteria. Based on an appropriate representation of the uncertainty sources (related to the input data and to the expert diagnostic), we then propose a methodology that integrates the uncertainty in the final output of the collapse susceptibility assessment and provides a confidence indicator useful within the decision-making process. The proposed methodology is applied to the Arras territory in the North of France, where abandoned chalk pits (dating back to the Roman ages) and war saps (i.e. covered trenches) located in the vicinity of the First World War front lines both raise difficulties for urban planning
\end{abstract}

Keywords: Cavities; Susceptibility assessment; Regional scale; Expert judgement; Weight of Evidence; Fuzzy set.

\section{Introduction}

The Earth's subsurface has, throughout history, been intensively worked not only for extracting material, as testified by the vast number of quarries and marl pits, but also for various other reasons resulting in underground structures as varied as war saps (covered frontline trenches), underground shelters, troglodyte dwellings, etc. (LCPC, 2002). In addition to these anthropogenic structures are the «natural » cavities such as the karsts in limestone environments. The existence of most of these underground cavities, classified as «abandoned », is unknown whereas voids can extend several tens of metres.

It is estimated that France contains more than 500000 of such underground structures whose partial or total ruin can have considerable socio-economic consequences for the community (Van Den Eeckhaut et al., 2007; Gutiérrez et al., 2008). For example, in the French region of Picardy alone, more than 300 constructions were damaged through cavity collapse following the winter rains of 2000-2001 (Bouchut and Vincent, 2002). These events can be sufficiently violent to cause human loss. Thus, in 1961, the collapse of an underground chalk quarry in the Paris suburb of Clamart caused the destruction of 20 buildings with the death of 21 people (Josien, 1995).

In France, cartographic tools known as Risk Prevention Plans (RPP), have been developed at municipal scale for determining cavity-associated risks (MATE, 1999). However, faced with both the number and the diversity of such abandoned cavities, the authorities require decision-aid tools to 
be able to rank the risks at spatially larger scales (such as grouped-municipality, if not regional scale) and manage the resultant uncertainties (Waltham et al., 2005). The present study puts forward a methodology in answer to these expectations.

Contrary to other natural phenomena, no single random variable can be identified for the overall measurement of the dreaded event, i.e. cavity collapse. In most cases, the studied underground structures are not accessible, which eliminates the use of a systematic deterministic approach. The particularity of mining cavities is the precision often provided by the existence and knowledge of mine plans and geometric parameters, even when incomplete. In the general case, we are concerned with limited and non-exhaustive input data, seldom supported by geometric and mechanical parameters. Being given the specificity of the studied natural phenomenon, the only predictive models that can be established consist in expressing the spatial probability of a surface instabilities appearance, known as "susceptibility". Two approaches can be commonly proposed in the view to assess the level of susceptibility: the one being based on empirical methods and the second one on the quantification of this levelby means of mathematical and statistical tools. In both cases, we have to be deal with with multiple and locally highly variable, controlling factors mainly based mainly on the judgement and information of an expert panel.

Where purely empirical methods are concerned, in France, methodological guides has been produced for assessing underground-cavity susceptibility in general (LCPC, 2002) or dedicated, for example, for the marl-pits of Upper Normandy (LCPC, 2008) or for mining cavities (INERIS, 2004). These guides develop a phenomenological approach based on analysing the rupture mechanisms and generally resulting in a qualitative spatial ranking of the susceptibility based on a weighting adjusted by experts. The application of a scoring and classification procedure has been commonly applied for ranking the collapse susceptibility of karstic cavities (Forth et al. 1999; Kaufmann and Quinif, 2002; Zhou et al., 2003; Cooper, 2008; Guerrero et al. (2008)). One major limitation of such an approach is the choice of the weightings, which is highly dependent on expert judgements (i.e. subjectivity), hence widely varying from one expert to another.

To compensate for this shortcoming, a large variety of rigorous mathematical and statistical tools have been introduced enabling one to quantify the probability between empirically established relationships without introducing expert subjectivity. Thus, White (1988) used the nearest neighbour analysis to interpret the spatial distribution of sinkholes, Mancini et al. (2009) used a multicriteria decision analysis to combine several quantitative hazard factors controlling the subsidence of a salt mine in order to score the hazard. Gao and Alexander (2003) and Bruno et al. (2008) used a decision tree, Lamelas et al. (2008) chose logistic regression. Applying several karst susceptibility assessment methodologies to the Ebro Valley, Galve et al. (2009) noted that models derived from the nearest neighbour distance and sinkhole density were more reliable than the probabilistic or heuristic methods. These tool types, however, are only based on the initial collection of data and thus favour the best informed sectors so that the susceptibility assessment might result in outlining the sectors where the information on the cavities is available. Thus, a major limitation of these approaches is that they are unsuited to an inventory that is known to be scarce and incomplete. The quality and precision of these approaches rest in fact on the exhaustiveness of the inventory, the realization of which is limited notably by the size of the study area. Introduction of the expert's subjectivity because of his knowledge of the regional context is thus essential in order to fill the gaps of the data-gathering phase.

Overlapping these methodological approaches and in the view to overcome the usual limitations encountered within commonly-used collapse susceptibility assessments of underground structures, an alternative is proposed in this article fulfilling the following requirements: (1) providing a useful tool for decision-makers and regional planning managers; (2) being flexible and adaptable to all kinds of cavity and specific local conditions; (3) enabling to take into account expert judgements of all types (geological, geographical, historical, engineering, etc.) whilst introducing analytical tools that control the weight of expert's subjectivity; (4) enabling to use existing punctual data collection while, at the same time, overcome any deficiency and/or lack of this collection.

The present article is organized as follows. In a first section, the general principles adopted for 
collapse susceptibility assessment of abandoned underground structures is described. In a second section, we shall see the adopted mathematical tools developed to manage the multiple uncertainty sources associated with the assessment. We shall also see that these tools depend on the nature of the criteria used. They are adapted either from the "weight-of-evidence" approach, which has been widely used in the field of mineral exploration (Bonham-Carter, 1994) and further applied for geohazard assessment, or from the "fuzzy set" theory (Zadeh, 1965) to deal with imprecision and incompleteness of available data. Based on an appropriate representation of the uncertainty sources, we then propose a methodology that integrate the uncertainty in the final output of the collapse susceptibility assessment and synthesize a confidence indicator useful within the decision-making process to assess the sensitivity of the results to the inputs. Finally, the use of the proposed methodology is illustrated for the Arras region of Northern France (section 4).

\section{Methodology for assessing collapse susceptibility}

\subsection{Definition of susceptibility}

The susceptibility of a surface disturbance (i.e. ground instability) measures the spatial probability of its appearance at the surface, without any reference to a temporal frequency associated with the hazard (Galve et al., 2009). This susceptibility level is a decision indicator for the decision maker, and is here assessed quantitatively as an "index".

From a practical point of view, the Collapse Susceptibility (CS), i.e. the susceptibility of a collapse appearing at the surface, is commonly estimated as the crossing of two separate susceptibility values, i.e. the Presence Susceptibility (PS) and the Rupture Susceptibility (RS), because regarding the large spatial scale considered, each of these susceptibility values can be assessed from independent controlling factors (see discussion in section 4). The first term PS corresponds to the susceptibility of cavities being present, whereas the second term RS corresponds to the susceptibility of the overlying ground (overburden) rupturing provided that a cavity is actually present. Thus, the latter susceptibility of the rupture process of the overburden is assessed in a "worst-case" situation because the presence of a cavity, i.e. the presence of void, is an additional factor increasing the ground rupture tendency.

From a mathematical point of view, the operation consisting in merely multiplying both susceptibilities to obtain the final collapse susceptibility implies that the two considered events are independent. This can be justified by the application of the Bayes theorem (see eq. (1)) considering that the presence of a cavity given the occurrence of a collapse event can be considered "certain" (i.e. the susceptibility is one).

As an illustration, let us consider a voluminous cavity below a massive resistant granitic overburden will present no surface risk. Conversely, a thin fractured and weathered limestone cover will not contain the propagation of instability, provided that a cavity can exist at the same place. Notice that although we focused here on brittle deformations that are the more damaging for the surface, such an approach could also be applied to plastic deformations that control ground instabilities such as settlement or subsidence.

\subsection{Principles of the methodology}

The study area is divided into homogeneous sectors for each of which one calculates a susceptibility index. The desired susceptibility index (here, that of the collapse susceptibility, CS) derives from two susceptibility values (here PS and RS) assessed in parallel as outlined in Fig. 1. The calculation of each value is a three-step process involving:

- Step 1: an inventory of existing data and a collection of information (geological and historicoeconomic) on the local context. This step is described in section 2.2.1.;

- Step 2: a list of relevant controlling factors (i.e. criteria) identified by experts from Step 1, the expertise being the central aspect of the method. This step is described in section 2.2.2 and the key role of expertise is further discussed in section 2.3.; 
- Step 3: a specific susceptibility map for each identified criterion starting from a quantitative index (for which the calculation method is described in section 3 and illustrated in section 4.3.). Such an approach is easily integrated into a GIS (Geographic Information System) and the final collapse susceptibility map is then calculated by crossing the presence and rupture susceptibility maps, each of them resulting from independent step 1, 2 and 3.

[Fig. 1 about here]

It should be noted that a specific susceptibility map is assessed for each cavity type. The characteristics of the disturbance expected at the surface and the controlling factors are notably highly dependent on the characteristics of the cavities (geological nature, dimension, location, depth, etc.), which vary greatly according to their type. To assess an overall susceptibility, regardless of cavity type, would be senseless.

\subsubsection{Step 1: Data collection}

The data collection step aims at gathering the local information in general (geological, historicoeconomic...) and especially, the inventoried punctual data. More precisely, it requires two distinct inventories for each type of cavity: an inventory of the existing cavities and an inventory of the associated surface disturbances. The two inventories do not necessarily have to be balanced in terms of number. In some French Departments, such as Paris or Gironde (southern France), quarry plans enable the compilation of very exhaustive cavity inventories, whereas in other regions, such as Picardy, Normandy (northern France), etc., one finds a large amount of surface disturbances but little information on the marl pits.

The inventories must be sufficiently supplied so as to be, according to the expert's opinion, representative of the state of both cavities and collapses, in the studied area. It should be noted, however, that an inventory considered as non-representative of the considered situation should be completed with data of similar neighbouring areas and thus increase the representativeness of the highlighted spatial correlations.

Surface disturbances related to the presence of an underground cavity can be of varied types such as generalized collapse, sinkhole, subsidence, settlement, etc. While deciding focusing on "collapse" phenomenon, the inventory should gather, so far as possible, the ground instabilities connected to such brittle deformation (i.e. collapse, sinkhole...). In this article, these specific types of ground instabilities are assigned to the generic term "disturbances".

\subsubsection{Step 2: Controlling factor (i.e. criterion) identification}

Two kinds of controlling criteria have to be identified for each cavity type : those that justify the spatial distribution of the cavities within the study area (e.g. geological nature, depth of the workable formations, etc.) and those that justify the collapses distribution (e.g. thickness of the cover rock, variation in groundwater level, nature of the overburden, etc.). Actually, it is considered that future disturbances will occur under similar conditions to past disturbances. These controlling factors can be classified into two types: «qualitative » when concerning qualitative indications (lithological type, historical sectoring, etc.) and « quantitative » when they can be associated with a measurable order (depth, distance, resistance, etc.). It should be noted that the process of identifying the appropriate criteria is beyond the scope of the present article, which focuses on managing the expert information and the associated uncertainty once the controlling factors have been defined.

\subsection{Key role of the expertise}

Integrating the uncertainties helps improving the risk management (Merad et al., 2004). In situations where a great deal of data are available, such as when dealing with industrial risk assessment or car accidents, a commonly used methodology for representing uncertainty is based on probabilistic tools (e.g. Baudrit and Dubois, 2006). In many cases and for many risk sources, 
however, particularly in the field of georisks (e.g. Karimi and Hüllermeier, 2007, Cauvin et al., 2008 \& 2009), the data available for hazard assessment can be particularly scarce and is often associated with imprecision and incompleteness due to spatial and financial constraints. Such uncertainties are usually named "epistemic", because they are knowledge-based in contrast to aleatoric uncertainties, which are inherent to the considered physical process (Ellingwood and Kinali, 2009). In these cases, it is difficult to use common mathematical tools for the uncertainty representation (Helton and Oberkampf, 2004; Baudrit and Dubois, 2006).

It is in this context that the expert's role is essential. At the core of the method (Fig. 1), the expert, on the basis of his experience and his regional knowledge, synthesizes and interprets the commonly imprecise, if not vague, information obtained from the inventory and the geological and historicaleconomic contexts. As several authors have already pointed out relative to all types of underground structure (Upchurch and Littlefield, 1988; Benson et al. 2003; Hubbard, 2003; Brinkmann et al., 2008), the essential aspect of the expertise is the identification of the theoretical controlling factors regulating the occurrence of the disturbances, i.e. the equivalent of the step 2 of the methodology. We propose introducing analytical tools that enhance the expertise process while managing several forms of epistemic uncertainty. It is a question of integrating two of the four types of uncertainty that, according to Cauvin et al. (2008), mar the risk analysis procedures: the "expert uncertainty" and the "input data uncertainty". More precisely, we propose to address the following types of uncertainties :

- UNC 1: non-exhaustiveness and heterogeneity in the spatial distribution of the inventory data ("data uncertainty");

- UNC 2: imprecision of the cavity and collapse inventoried data (poor location, information lacking, etc.) ("data uncertainty");

Both of these "data uncertainties" are making up the initial knowledge of the studied geological phenomenon, which complicated the analysis. We will take into account two other sources of uncertainty, linked to the analysis the experts lead from the analysis of this inventoried data:

- UNC 3: uncertainty associated to the expert analysis and interpretation ("expert diagnostic uncertainty");

- UNC 4: imprecision or variability of the cartographic data related to each criterion on the basis of which the index is fixed ("cartographic data uncertainty").

It is important to note that we do not question the basic hypothesis on which the method is based, namely that there is a correlation between the geological event and the identified criterion. Thesemore general sources of uncertainty, which are not taken into account, correspond to the uncertainties identified by Catvin et al. (2008) such as the "resources" type uncertainty related to poor knowledge of the phenomenon.

\section{Managing expert uncertainty (Step 3)}

In this section, we propose mathematical tools for representing and processing with flexibility the expert information while managing the different kinds of associated uncertainty.

\subsection{Addressing UNC 1: use of a density function}

A specific tool has been developed to quantify the level of susceptibility associated with qualitative controlling factors, e.g. geological nature of the substratum, historical area, etc.

In a classical approach, the relationship between the spatial distribution of the cavities (or of the surface ground disturbances related to a cavity) and information of qualitative nature (e.g. the geological nature of the substratum)-would be assessed by assigning a weight to each geologicat formation, reflecting the expert knowledge en each formation (historical presence of quarries, qualitative estimates of rock strength, etc.). The major limitation of such an approach resides in the quantification of these weights and as an alternative, we propose a data-driven method based on the "weight of evidence" approach. 
This approach was originally developed for mineral exploration activities (for instance in the field of gold mineralization research, Bonham-Carter, 1994) and recently used in the field of landslide hazard assessment to quantify landslide triggering susceptibility (Rezaei Moghaddam et al., 2007; Neuhäuser and Terhorst, 2007; Barbieri and Cambuli, 2009) and begins to be used for assessment of ground subsidence susceptibility related to abandoned mines (Oh and Lee, 2010).

The attractive feature of this method is its flexibility when, for example, geotechnical or hydrogeological data are unavailable at the regional scale (Rezaei Moghaddam et al., 2007;

Neuhäuser and Terhorst, 2007).

Formally, the "weight of evidence" approach is based on the statistical Bayesian paradigm using the concept of prior and posterior probability. For illustrative purposes, let us consider the qualitative factor "geological nature of the formation" usually used to explain the presence stseepility assessment of abandoned eavities. We define the event $E$ as the one referring to this geological factor ; the associated probability is denoted $\mathrm{p}(E)$. Similarly, the event $G$ refers to the presence of cavity which probability of occurrence is denoted $\mathrm{p}(G)$.

The probability $P(G \mid E)$ of the a posteriori outcome of $G$ given $E$ reads after the Bayes theorem as follows:

$$
P(G \mid E)=\frac{p(E \mid G) \cdot p(G)}{p(E)}
$$

Defining the "odd" as $\theta(G)=p(G) / p(\bar{G})$, the weight of evidence W can be expressed as follows:

$$
\log (\theta(G \mid E))=\log (\theta(G))+\log \left(\frac{p(E \mid G)}{p(E \mid \bar{G})}\right)=\log (\theta(G))+W
$$

The weight $W$ is directly proportional to the influence that the controlling factor $E$ has on the presence of the underground cavity $G$, hence measuring the modification brought by the outcome of the event $E$ on the probability p $(G)$ of an a priori outcome of the event $G$.

In the landslide case, Barbieri and Cambuli (2009) assess $W$ considering the area affected by landslide phenomena in the considered class (i.e. in the considered geological formation), the total area affected by landslide, the total area of the considered class and the total area of the studied zone. We adapt this approach for cavities: since the area covered by these structures (or the area of the ground disturbances generated by such structures) can be neglected compared to the large area of the studied zone (regional spatial scale), the quantity of interest describing the underground structure is simply the number of inventoried cavities.

Let us divide the space $\Omega$ into spatial units $\omega_{\mathrm{i}}$, following the outcome of one qualitative criterion (in the considered case, the geological nature of the substratum), as depicted in Fig. 2A. Defining $a_{\omega_{i}}$ as the area of the considered class and $n_{\omega_{i}}$ as the number of cavities in this class, $A_{\Omega}$ and $N_{\Omega}$ correspond to the total area and the total number of cavities of the whole studied space $\Omega$. The weight of evidence $W_{\omega_{i}}$ associated to the spatial unit $\omega_{\mathrm{i}}$ reads as follows:

$$
\begin{gathered}
W_{\omega_{i}} \approx \log \left(\frac{n_{\omega_{i}} / N_{\Omega}}{a_{\omega_{i}} / A_{\Omega}}\right)=\log \left(D_{\omega_{i}}\right) \\
\sum_{i} n_{\omega_{i}}=N_{\Omega} \& \sum_{i} a_{\omega_{i}}=A_{\Omega}
\end{gathered}
$$

Noteworthy, such an approach can be easily adapted to the event $E$ "overburden rupture" from the outcome of event $G$, presence of surface disturbances.

In practice, each identified qualitative criterion (i.e. controlling factor) leads to a space partition and 
a definition of a density function $D_{\Omega}$ which is thus "stepped", constant and equal to $D_{\omega_{i}}$ in each spatial unit.

We shall illustrate our case by focussing on the event $G$ : "presence of quarries in the Loiret Department of France". In this case, the spatial units associated to the criterion "lithological nature of the substratum" (occurrence factor $E$ ), are shown on Fig. 2B. Each geological unit is associated with a single index tied in to the observed data (and not only on an expert judgement) using the density function allowing to manage the heterogeneity of the data spatial distribution within the units by extending the localized inventoried information. Thus, the commune of Ingrannes, without any known cavity, will be assigned, considering this criterion, the same index as the city of Orléans located in the same spatial unit corresponding to the geological formation of "Pithiviers" Limestone, and for which a detailed inventory is available (Fig. 2B). Though this approach allows to define rigorously and objectively quantitative index assigned to qualitative spatially-distributed controlling factors, the key aspect resides in ensuring that the inventory of the collected data (number of underground structures, number of ground disturbances) is representative as outlined in Billa et al. (2004).

[Fig. 2 about here]

\subsection{Addressing UNC 2: use of a membership function}

A specific tool has been developed to quantify the level of susceptibility associated with quantitative controlling factors, e.g. thickness of the overburden, depth of the water table, etc. The fuzzy logic (e.g. Ross, 1995) based on the fuzzy set theory (first introduced by Zadeh, 1965) is particularly suited for formalizing empirical and intuitive reasoning which the experts may establish from a few vague data. In particular, it enables one to manage the so-called "threshold effects" generally introduced at the class limit level. These features make the methodology, which was brought to rock mechanics by Brown (1979), particularly well suited for geotechnical problems (e.g. Elshayeb 2005). Recently, Saboya et al. (2006) and Kanungo et al. (2006) both used fuzzy logic for assessing landslide susceptibility.

Let us consider the concept of membership function, which defines how each element $x$ of the input space $X$ (also named "universe of discourse") is mapped to a degree of membership (denoted $\mu$ ). Under the classical theory of Boolean logic, the membership function of a set $A$ is simply defined as a binary function that takes the value $\mu(x)=1$ if the element belongs to $A$ and the value $\mu(x)=0$, otherwise. In Fig. 3A, the set $A$ is graphically represented by a clearly defined boundary. However, faced with information tainted by uncertainty, it may be difficult (or impossible) to accurately define the location of this boundary. In this context, the fuzzy set theory introduces the concept of a set without a crisp, hence clearly defined, boundary. Such a set $\tilde{A}$ can contain elements with only a partial degree of membership (scaled between 0 and 1) as defined by equation 5 .

$$
\begin{aligned}
& \mu_{\tilde{A}}: X \rightarrow[0.1] \\
& \tilde{A}=\left\{x, \mu_{\tilde{A}}(x) / x \in \tilde{A} ; \tilde{A} \subset X\right\}
\end{aligned}
$$

Graphically, the boundary of the fuzzy set $\tilde{A}$ is a progressive boundary (Fig. 3B), so that the element $x_{2}$ depicted in Fig.3B is located in the "fuzzy" zone between the so-called "certain" boundaries (boundaries respectively assigned to $\mu=0$ and $\mu=1$ ) and is associated with a $66 \%$ degree of membership, whereas under the classic Boolean theory, it is entirely excluded from unit A (Fig. 3A).

[Fig. 3 about here] 
Considering cavities, the fuzzy set theory is used to quantify the influence of each quantitative criterion for both dreaded geological events "presence of an underground cavity" and "overburden rupture".

Let us consider the criterion "depth of the worked geological formation", frequently used to justify the presence of a quarry. In this case, the input space (i.e. universe of discourse) is all potential depths of the worked geological formation. On the basis of the collected data (Fig. 4.A.), as well as of regional knowledge of the context (both geological and historical), the expert could, for instance, state that "in this type of geological formation, I am certain that there are quarries at less than $15 \mathrm{~m}$ depth and that, for technical mining conditions, no quarry could be present below $50 \mathrm{~m}$ ". The fuzzy set $\tilde{A}$ is here defined as the depths to which one may encounter quarries, accompanied by a degree of membership measuring their influence on the event "presence of a cavity". Taking the above example, Fig. 4.B. shows that the depths within the $0-15 \mathrm{~m}$ interval (Zone I) are characterized by the maximum degree of membership. Below this depth, in the 15-50m interval (Zone II of Fig. 4.B.), the degree of membership decreases until below 50m depth (Zone III, Fig. 4.B.), where the expert estimates that the presence of a quarry is not possible, which correspond to a null degree of membership. Under the traditional approach, if the threshold is fixed at $15 \mathrm{~m}$, a cavity located at $16 \mathrm{~m}$ is automatically and unfavourably placed in the same class as that located at $50 \mathrm{~m}$. The entire sense of the "membership function" is thus that it frees one from data insufficiency (Ercanoglu and Gokceoglu, 2004). Here the proposed transition is linear (Zone II), but the expert could assume a nonlinear curve. For instance, if the expert has knowledge (or observations) indicating that while values located within zone II are possible, they are nevertheless very unlikely, convex functions can be used (Baudrit et al., 2007). Note that the membership function joins the type of continuous function defined by Thierry et al. (2009) to assess gypsum dissolution collapse susceptibility from observations.

[Fig. 4 about here]

\subsection{Addressing UNC 3: sensitivity to the experts' choice}

The membership function provides flexibility in the definition of the class of the controlling factors by introducing the notion of gradual membership. This function reflects the judgment of a single expert by means of thresholds defining the different zones of varying degrees of membership (Fig. 4.B.), which can vary from one expert to another. To refine the uncertainty representation provided by the membership function, different expert judgements should then be taken into account i.e. a multiple of sources of information. Noteworthy, such an approach is similar when observing a given physical phenomenon, which often relies on a variety of observational techniques to build confidence in the physical process evidence.

A variety of methods exist to synthesize the variability of the judgements provided by the expert panel ; we choose to summarize it by a pair of membership functions, respectively corresponding to a "pessimistic" and an "optimistic" distribution (respectively red and blue distribution, Fig. 5). The uncertainty that the experts associate to their diagnosis is quantifiable by the difference between the results obtained by the two functions. For the case depicted in Fig. 5, the experts are certain of their diagnosis above 50m depth and below $15 \mathrm{~m}$ depth, but between these two values, the degree of membership is accompanied by an uncertainty represented by a range of values, which is maximal here at $35 \mathrm{~m}$ depth. To facilitate the decision-making process, it is proposed to compute a single susceptibility index as a weighed average of both membership functions (optimistic and pessimistic) based on the approach of Hurwicz (1951) in the field of decision-making under ignorance. The choice of the weights is subjective and reflects the attitude of the decision-maker with respect to risk (Baudrit et al., 2007). For instance, a weight of $0 \%$ corresponds to a situation of complete aversion to risk and the pessimistic bound is privileged. In this study, we choose a weight of 50\% between the optimistic and the pessimistic view so that each quantitative criterion at any point of 
the studied territory is assigned a "medium" susceptibility assessment accompanied by a variation range related to the uncertainty of the expert's judgement.

[Fig. 5 about here]

\subsection{Addressing UNC 4: integrate the cartographic data imprecision}

The value of the susceptibility index closely depends on the quality of the cartographic data associated with the identified criteria, i.e. the inputs of the membership function at each given location of the territory. In geostatistics, the kriging variance supplies, for example, an estimate of the precision of the map displayed (Chilès and Delfiner 1999). In the absence of a local estimate like this, the imprecision can also be given in a uniform fashion over the studied domain (i.e. 'the precision of the measurement of the depth of the substratum is accurate to within 3 metres'). This information enable to defer the effect of the measurement imprecision (whether uniform or variable) on the final susceptibility index at each point (or at some only) of the studied territory. Figure 6 shows the influence that an imprecision of $\pm 3 \mathrm{~m}$ on the depth, could involve on the degree of membership at a given location (UNC4), integrating also the uncertainty the expert associate to their diagnosis at each depth (UNC3). Although the final value will be estimated by a single index (that worth 0.5 at a depth of $30 \mathrm{~m}$ in the example illustrated in Fig.6), the global uncertainty introduces the potential range for the degrees of membership integrating UNC 3 and UNC 4 (e.g. the degree of membership at a depth of $30 \mathrm{~m}$ could actually range between 0.10 and 0.75 , Fig. 6 ). The weight of the input data imprecision in the value of the overall confidence indicator is useful for risk management purpose.

[Fig. 6 about here]

\section{Mapping of collapse susceptibility incorporating uncertainty}

The objective of this section is twofold: 1$)$ describe the methodology to compute the final collapse susceptibility map and the information on uncertainty to support decision-making ; 2) discuss the results in particular considering the applicability of other commonly-used approaches, the deterministic and the statistical (probabilistic) approaches, which do not have the shortcomings of any method based on the contribution of an expert. In this view, the Arras territory located in the North of France is used as an illustrative case.

\subsection{Context of Arras territory}

The Arras territory (Fig. 7) corresponds to a grouped-municipality of 20 towns (43 000 inhabitants) covering a total area of $170 \mathrm{~km}^{2}$. Considering the geological setting, the substratum is composed of a chalky geological formation (Coniacian, Upper Cretaceous) overlain by a Quaternary cover of silt and loess over the whole region (Fig. 7).

The cavities risk collapsing is a major concern for the territory management.Two types of underground structures more particularly raising difficulties:

- Underground quarries of phosphated chalk (i.e. Chalkpits), date back to the Roman times for the first underground workings. In addition to the use of lime as an amendment, nodular chalk was used in abundance as dimension stone during the 16th and 17th centuries. Worked in so-called "catiches" i.e. corresponding to bottle-shaped underground mining galleries or by room and pillar, they are specifically adapted for construction and represent most of the inventoried cavities. In addition, each Arras village is likely to present a few "refuge"-type cavities (commonly below churches, monasteries, convents, castles, etc.), some of which used and/or modified pre-existing underground quarries (Marie et al., 2004). This feature derives from the Arras wars in the middle Ages; 
- First World War saps (i.e. covered trenches) are military underground structures dating back to the First World War (1914-1918) and generally consist of a trench and an inclined gallery that leads to an underground room, enabling the army troops to take shelter or try and penetrate the enemy lines (LCPC, 2008). The network of wartime trenches is generally marked by underground shelters (every 20 to approximately $50 \mathrm{~m}$ ), which were very partially filled in after the war. The wall rock of these cavities was situated, when possible, in the chalk formation to achieve a better drainage whereas the roof generally reached the silt formation (Poitout and Piraud, 2003).

\section{[Fig. 7 about here]}

The cavity inventory was primarily based on the French national public database (http://www.bdcavite.net/), which collects all the "known" underground structures at the national scale and aims at informing citizens, hence contributing to the natural hazards prevention policy led by French authorities so that a total number of 300 underground quarries were identified and localized in the studied territory (outlined in Fig. 7 by a yellow star-type marker). The inventory of the war saps (outlined in Fig. 7 by a linear black symbol) was mostly based on military maps compiled by the Military Staff Office which locate the French and German trenches and so, the positions of the saps in the studied territory. Some sectors like the Canadian National Vimy Memorial Site are very well documented, but in general, availability of this information from archival sources remains, however, patchy (Hutchinson et al., 2008). The collapse inventory was, however, relatively scarce with 48 collapse events reported in the existing national database (http://www.bdmvt.net/).

Hence, the Arras territory presents numerous old mining structures of small to moderate dimensions in a context characterized by an a priori "simple" geological setting, but by a complex historical background. Some of these cavities have been abandoned several decades or centuries ago so that a large number of them have been lost from the collective memory (in relation with memory loss syndrome well known in the field of mine closure, ISRM, 2008) i.e. a majority of these cavities have not necessarily been localized yet. Recently, the intense rainfall events of winter 2001- 2002 were followed by numerous surface damages and sinkholes. These collapse events were primarily associated to "forget" underground structures, which would not have been discovered without the occurrence of these meteorological events. The regional authorities urgently prescribed 27 Risk Prevention Plans (RPP), but without any other means of ranking the priority than choosing the towns that were already affected by collapses. For future prescription of RPP, the local authorities advocated the development of a methodology to set priorities under budget constraints, in particular regarding new data collection, with a particular care paid to the treatment of regions with very scarce data.

\subsection{Susceptibility assessment and discussion}

The susceptibility assessment can be based on deterministic methods, which apply principles such as limit equilibrium and finite element techniques. Cauvin et al. (2009) provides an illustration of such an approach applied in the field of post-mining hazard assessments. These models require standard rock mass characterization such as rock strength, fracture network description, groundwater pressures, but also the description of cavity geometry, excavation and support techniques. The latter data are seldom available for the considered underground structures of the Arras territory as they were mostly constructed in a "handcrafted" manner and restricted to the underground structures accessible for inspection. Applying a deterministic approach based on a geomechanics stability assessment as the one carried out at the Vimy Memorial Site (Hutchinson et al., 2008) would have then been tedious and the generalization to the whole sector would have been questionable. Noteworthy the area of the site studied by Hutchinson and co-authors reaching 0.91 $\mathrm{km}^{2}$ to be compared to the $170 \mathrm{~km}^{2}$ of the whole studied territory. Hence, the inherent nature of 
types of underground structures eliminated a systematic deterministic approach.

In this context, pertinent controlling factors were then defined (Table 1) by a panel of local experts (geologists, hydrogeologists, historians, etc.), backed up by the spatial distribution of the recorded cavities and ground instabilities (step 2 of the methodology, see section 2.2). Note that the analysis (presence and rupture controlling factors identification) was carried out independently for each cavity type.

\section{[Table 1 about here]}

An alternative objective way of developing susceptibility mapping is by correlating statistically the identified set of factors explaining the presence of the considered cavities and the rupture process from the recorded past observations (cavity and collapse inventoried). This can be achieved by means, for instance of multi-variant regression analysis with the use of GIS. An example of such an application is provided by Galve et al., 2008. In the context of the Arras territory, the application of a pure statistical approach (also named probabilistic) was liable to result in very coarse and even misleading correlations, because the historical inventory was scarce especially for the collapse inventory (with only 48 events recorded within a region of $170 \mathrm{~km}^{2}$ ), not to mention information of poor quality, e.g. on the origin of the disturbance and on the cavity at stake, which-rarely adequately filled in database.

Faced with incomplete information, the apparent statistical fit may have provided a false sense of accuracy, because the statistical correlations and the results in terms of susceptibility outcomes were highly sensitive to small changes in the distribution of inventoried cavities or recorded past events. This was shown through cross-validation procedures (denoted as "random validation" in Galve et al. 2008) consisting in: (1) randomly partitioning the original set of observations into two subsets (e.g. the first one composed of $90 \%$ of the original observations and the second one of $10 \%$ ); (2) performing the susceptibility assessment using the first subset and (3) validating the analysis on the second one. In this manner, we showed that the susceptibility of regions where collapse events were actually observed (corresponding to the second subset) changed from high to low values. Hence, in the context of Arras territory, the application of "pure" statistical correlations would have been of doubtful validity, particularly when used for extrapolation in zones with no data.

An alternative was then proposed relying on the statistical analysis of available data regarding factors viewed as relevant and prominent given the local context (see Table 1), but tempered by experts' judgments to compensate for lack of observations. Such an approach required adequate mathematical processing tools (described in section 3) to deal with the shortcomings of traditional scoring systems based on experts' judgments (as outlined in the introduction).

The studied sector is then decomposed into spatial grid of elements. The choice of the spatial extent of the grid is based on the the cartographic support precision related to each criterion. Thus, the Arras territory was divided into $2 \mathrm{~km}$ grids, because the criteria were mapped based on 1: 50000 geological maps, on kriging-based procedures using a very few boreholes available in the region (hence associated with a large kriging-variance) and on historical data on the front lign location (also associated with imprecision).

Each controlling factor was then associated with a susceptibility index calculated at each element of the spatial grid (Step 3 of the methodology, see section 2.2). The index was calculated using one or other of the previously defined tools, according to whether the associated criterion was categorized as "qualitative" or "quantitative".

\subsection{Final outputs and use for decision-making}

To compute the final susceptibility map, a common method would simply consist in adding up the indices, each of them level-headed by empirical weights attributed to each controlling factors (Forth et al., 1999; Sanchez et al., 2007). Another approach relies on mathematical optimization (e.g. Soriano and Simón, 1995), which has no physical significance in our case and requires a large 
amount of data. Due to the difference natures of each controlling factors (i.e. the mathematical form of their representation), we propose an alternative procedure for the combination of all indices:

- each qualitative criterion is given the same significance by introducing no weighting, and is considered to have a priori, the same role in the distribution of cavities or disturbances.

Thus, when there are several qualitative criteria, the indices given by the density functions (value of same dimension, scaled between 0 and 1 ) are simply added together. The importance of one criterion compared to another is implicitly contained in the spatial distribution of the input sample and thus in the values calculated by the density function: the more discriminating a criterion is, the greater the influence of the associated index will be in the overall value;

- to combine the indices of the membership functions (when there are several quantitative criteria), one uses fuzzy logic aggregation tools ("MAX" operator), i.e. the upper envelope of the intersection of all these functions. This procedure enables one to incorporate information without compensating for the criteria, emphasizing locally the most characteristic parameter of the susceptibility (Ercanoglu and Gokceoglu, 2004).

- finally, the presence or rupture susceptibility (PS or RS) results from the product of the two preceding terms. Since the value given by the membership function varies from 0 to 1 , the membership function thus operates as a filter on the density functions results.

The flowchart in Fig. 8 illustrates the mathematical aggregation operators for assessing the rupture susceptibly (RS) of the chalkpits in the Arras region.

[Fig. 8 about here]

The final output (Fig. 9C) is a susceptibility map resulting from the crossing of a presence susceptibility (PS) map (Fig. 9A) and a rupture susceptibility (RS) map (Fig. 9B). As a result, the four riskiest sectors are clearly outlined in the studied territory (red cell in Fig. 9C). Noteworhty these identified sectors do not automatically correspond to the more documented area. On the basis of the three independent maps (PS, RS and CS), the decision maker is provided with the whole information whether it would be on the presence susceptibility, on the rupture susceptibility or on the final output in terms of collapse susceptibility. This allows a better understanding of the factors controlling the risk and so a better communication about it. On this basis, the natural hazard prevention policy can be adapted, for instance, either focusing on the means to improve the localisation of cavities or on the better understanding of the rupture mechanics.

[Fig. 9 about here]

For illustrative purposes, let us consider the "c" town located in a zone where the presence susceptibility is qualified as "moderate to high" (Fig. 9A), whereas the rupture susceptibility is relatively low (Fig. 9B). The analysis shows that this sector is not concerned by collapsing, since the cavities present in this zone would tend to be stable (Fig. 9C). However, the first map (Fig. 9A) confirms that chalkpits may exist in this sector, which could become a new constraint to be taken into account for further underground projects.

Studying the sensitivity of these results to changes in the input values of the methodology, provides additional information on corresponds the uncertainty source UNC3 (uncertainty that the experts associate to their diagnosis, see section 3.3) and UNC4 (cartographic data imprecision, see section 3.4) to support decision-making.. In this view, the collapse susceptibility mapping (Fig 9C) is associated with a confidence indicator (Fig 9D) calculated as the maximum value of this indicator associated to each individual criterion. Thus, at any point of the studied territory, the decision maker 
is provided with useful guidelines for risk management, but also for risk communication (e.g. Ellingwood and Kinali, 2009):

(1) an estimate of the absolute uncertainty associated to the susceptibility index (i.e. a range of values for this index). As an illustration, let us consider the " $b$ " town, which is situated in a "moderate" collapse susceptibility zone (Fig. 9C). Fig. 9D indicates that this result is associated with a low level of confidence, hence should be considered cautiously, and the analysis should be completed with further investigations or additional collection of data to reduce uncertainty locally. On the contrary, the "low" collapse susceptibility zone concerning the "a" town (Fig. 9D) is more reliable as outlined in Fig. 9D ;

(2) the percentage of the uncertainty stemming either from the uncertainty in PS and RS as depicted in the percentage indicated in Fig. 9D.

For instance, unlike its surroundings, the level of confidence at the "d" town is low and mainly results from the uncertainty on on the rupture susceptibility (at $80 \%$ ), which is related to the choice of the thresholds for the definition of the membership function.

\section{Concluding remarks and discussion}

Assessing the collapse susceptibility of abandoned cavities at a regional scale is associated with large uncertainties that are mainly related to the very nature of the phenomena, but also to the difficulty in collecting exhaustive information at such a scale on often "forgotten" structures. In this context, the expert's role is essential, because he is able to synthesize the information resulting from the inventory and from the commonly imprecise, if not vague, criteria on the basis of his experience and his knowledge of the regional geological and historical and economic context.

We have developed two tools for processing this information in order to give flexibility to this step and manage the uncertainty inherent in the expert's information. One tool, based on the "weight of evidence" theory (Bonham-Carter, 1994), is for managing the uncertainty due to the heterogeneous spatial distribution of the data. The second tool, based on the fuzzy set theory (Zadeh, 1965), is for managing the uncertainty on the univocal definition of the class boundaries of the decision criteria. It should be noted that the method does not a priori fix the criteria for assessing the collapse susceptibility of underground structures in general, but offers management tools once the most relevant of these have been identified.

The quality of the obtained results depends entirely on the relevance of the selected criteria and thus on the understanding of the phenomena (Upchurch and Littlefield, 1988; Benson et al. 2003; Hubbard, 2003; Brinkmann et al., 2008). Although the method endeavours to control and limit the subjectivity of expert judgement, the expertise is still the central point. Its role is mainly in selecting the susceptibility criteria that must be independent, relevant and exhaustive to account for the phenomena. It would be wrong and "dangerous" to limit oneself to the most obvious criteria and ignore more complex criteria that also have a role in justifying the observed spatial distribution. The expert must also ensure that he draws up inventories that are sufficiently representative of the existing situation so as not to distort the construction of the tools.

Starting from the expert judgement, the developed method ends with a quantitative assessment of the susceptibility levels thanks to two mathematical tools that make it possible to determine the best weight reflecting the influence of each controlling criterion. It differs from the traditionally used approaches by:

- dealing with all types of criteria, knowing that density functions make it possible to extend qualitative information, while being strict concerning the weight allotted to the spatial units and freeing oneself of a subjective theoretical weighting;

- limiting the threshold effects classically introduced by the expert's judgement;

- freeing oneself of the spatial distribution heterogeneity of the initially existing punctual information: the analysis no longer favours the best documented sectors;

- limiting the weightings and compensatory effect when combining the criteria; 
- measuring the risk taken by the expert in his analysis, which allows him to remain prudent in the resulting diagnosis; This task implies assessing the expert's "reliability", aggregating the judgements provided by the expert panel and synthesizing them for practical use in decision-making process. The latter taskmay be tedious, especially when information is conflicting (e.g. Destercke and Chojnacki, 2008) and constitutes a perspective for further works.

Using the final cartographic results, territorial managers can quantify the issues affected by the collapse of each type of cavity and thus rank what they are likely to accept or reduce while integrating the uncertainty of the expert's diagnosis. The proposed maps enable them to access the information sources and have access to the technical arguments. The increased perspectives thus facilitate the acceptance of the hazard by the decision-maker and respond to planning and risk management requirements on a regional scale.

Acknowledgements

This work was financially supported by the French Environment Ministry and the BRGM and through the 'Barnier funds' allotted by the Pas-de-Calais (62) and Loiret (45) prefectures. The development of this project involved many BRGM specialists, all gratefully acknowledged. Particular thanks to Gilles Grandjean, Denis Moiriat, Thierry Winter, Mélanie Fontaine, Carole Lembezat. The authors would like to thank the grouped municipalities of Orléans and Arras for providing data on the study areas and the SDICS (Regional Department of Underground Quarry Inspection) for handing the military maps.

\section{References}

Barbieri, G., Cambuli, P., 2009. The weight of evidence statistical method in landslide susceptibility mapping of the Rio Pardu Valley (Sardinia, Italy). 18th World IMACS / MODSIM Congress, Cairns, Australia, 13-17 July 2009.

Baudrit, C., Dubois, D., 2006, Practical representations of incomplete probabilistic knowledge, Computational Statistics \& Data Analysis, 51, 86 - 108.

Baudrit, C., Guyonnet, D., Dubois, D., 2007, Joint propagation of variability and imprecision in assessing the risk of groundwater contamination, Journal of Contaminant Hydrology, 93, 72-84.

Billa, M., Cassard, D., Lips, A.L.W., Bouchot, V., Tourlière, B., Stein, G., Guillou-Frottier, L., 2004. Predicting gold-rich epithermal and porphyry systems in the central Andes with a continental-scale metallogenic GIS. Ore Geology Reviews 25 (1-2), 39-67.

Benson, R.C., Yuhr, L., Kaufmann, R.D., 2003. Assessing the risk of karst subsidence and collapse. Proc. 9th Multidisc. Conf. on Sinkholes and the Engineering and Environmental Impact of Karst 122, Huntsville, Alabama (2003), pp. 31-39 ASCE

Bonham-Carter, G., 1994. Geographic information systems for geoscientists: modelling with GIS. New York, Pergamon, 398 p.

Bouchut, J., Vincent, M., 2002. Recensement et analyse des mouvements de terrain survenus en 2000-2001 dans les arrondissements de Montdidier (Somme) et de Clermont (Oise). BRGM/RP51763-FR, 103 p, 38 figs., 3 tables, 3 apps., 2 pl.

Brinkmann, R., Parise, M., Dye, D., 2008. Sinkhole distribution in a rapidly developing urban environment: Hillsborough County, Tampa Bay Area, Florida. Engineering Geology 99 (3-4), 169184. 
Brown, C.B., 1979. A Fuzzy Safety Measure. Journal of Engineering Mechanics Division 105 (5), 855-872.

Bruno, E., Calcaterra, D., Parise, M., 2008. Development and morphometry of sinkholes in coastal plains of Apulia, southern Italy. Preliminary sinkhole susceptibility assessment. Engineering Geology 99 (3-4), 198-209.

Cauvin, M., Verdel, T., Salmon, R., 2009. Modeling Uncertainties in Mining Pillar Stability Analysis. Risk Analysis 29 (10), 1371-1380.

Cauvin, M., Salmon, R., Verdel, T., 2008. Dealing with uncertainties in the context of post mining hazard evaluation. Post-Mining 2008, February 7-8, Nancy, France.

Chilès, J.P., Delfiner, P. 1999. Geostatistics: modelling spatial uncertainty. Wiley Series in Probability and Mathematical Statistics, 695 p.

Cooper, A.H., 2008. The GIS approach to evaporite-karst geohazards in Great Britain. Environmental Geology 53 (5), 981-992.

Destercke, S., Chojnacki, E., 2008. Methods for the evaluation and synthesis ofmultiple sources of information applied to nuclear computer codes, Nuclear Engineering and Design, 238, 2484-2493.

Ellingwood, B. R., Kinali, K., 2009, Quantifying and communicating uncertainty in seismic risk assessment, Structural Safety, 31(2), 179-187.

Elshayeb, Y., 2005. Overcoming Uncertainties in Risk Analysis: Trade-Offs among Methods of Uncertainty Analysis, In: Nato Science Series: IV: Earth and Environmental Sciences 38, 287-295, Springer Netherlands.

Ercanoglu, M., Gokceoglu C. 2004. Use of fuzzy relations to produce landslide susceptibility map of a landslide prone area (West Black Sea Region, Turkey). Engineering Geology 75 (3-4), 229-250.

Forth, R.A., Butcher, D., Senior, R., 1999. Hazard mapping of karst along the coast of the Algarve, Portugal. Engineering Geology 52 (1-2), 67-74.

Galve, J.P. , Gutiérrez, F., Remondo, J., Bonachea, J., Lucha, P., Cendrero, A., 2009. Evaluating and comparing methods of sinkhole susceptibility mapping in the Ebro Valley evaporite karst (NE Spain). Geomorphology 111 (3-4), 160-172.

Galve, J.P., Bonachea, J., Remondo, J., Gutierrez, F., Guerrero, J., Lucha, P., Cendrero, A., Gutierrez, M., Sanchez, J.A., 2008. Development and validation of sinkhole susceptibility models in mantled karst settings. A case study from the Ebro valley evaporite karst (NE Spain), Engineering Geology 99 (3-4), 185-197.

Gao, Y., Alexander, E.C. Jr., 2003. A mathematical model for a sinkhole probability map in Fillmore County, Minnesota. In: Beck, B.F. (ed) Sinkholes and the engineering and environmental impacts of Karsts. Proceedings of the $9^{\text {th }}$ Multidisciplinary Conference, Huntsville, Alabama, 6-10 September. ASCE Geotechnical Special Publication 122, 439-449.

Guerrero, J., Gutiérrez, F., Bonachea, J, Lucha, P., 2008. A sinkhole susceptibility zonation based on paleokarst analysis along a stretch of the Madrid-Barcelona high-speed railway built over gypsumand salt-bearing evaporites (NE Spain). Engineering Geology 102 (1-2), 62-73. 
Gutiérrez, F., Cooper, A.H., Johnson, K.S., 2008. Identification, prediction and mitigation of sinkhole hazards in evaporite karst areas. Environmental Geology 53, 1007-1022.

Helton, J. C., Oberkampf, W. L., 2004, Guest Editorial: Alternative representations of epistemic uncertainty, Reliability Engineering \& System Safety, 85(1-3), 1-10.

Hubbard, D.A., 2003. Use of regional sinkhole mapping for sinkhole susceptibility maps, Proc. 9th Multidisc. Conf. on Sinkholes and the Engineering and Environmental Impact of Karst 122, Huntsville, Alabama (2003), pp. 61-71 ASCE.

Hutchinson, D.J., Diederichs, M., Pehme, P., Sawyer, P., Robinson, P., Puxley, A., Robichaud, H., 2008. Geomechanics stability assessment of World War I military excavations at the Canadian National Vimy Memorial Site, France, International Journal of Rock Mechanics and Mining Sciences 45 (1), 59-77.

Hurwicz, L., 1951, Optimality Criteria for Decision Making under Ignorance, Cowles Commission Discussion Paper no.370.

INERIS (Collectif), 2004. L'élaboration des Plans de Prévention des Risques Miniers. Guide méthodologique - volet technique relatif à l'évaluation de l'aléa, INERIS DRS-04-51198-R01, 125 p.

ISRM (International Society of Rock Mechanics), 2008. International Commission on mine closure - Mine closure and post mining management international state of the art, technical report, June 2008.

Josien, J.P., 1995. Diagnostic et caractérisation des aléas. Bulletin de l'Association Internationale de Géologie de l'Ingénieur 51, Paris, 95-111.

Kanungo, D.P., Arora, M.K., Sarkar, S., Gupta, R.P., 2006. A comparative study of conventional, ANN black box, fuzzy and combine neural and fuzzy weighting procedures for landslide susceptibility zonation in Darjeeling Himalayas. Engineering Geology 85 (3-4), 347-366.

Karimi, I. Hüllermeier, E., 2007, Risk assessment system of natural hazards: A new approach based on fuzzy probability Fuzzy Sets and Systems, 158(9), 987-999.

Kaufmann and Quinif, 2002. Geohazard map of cover-collapse sinkholes in the "Tournaisis" area southern Belgium. Engineering Geology 65, 117-124.

Lamelas, M.T., Marinoni, O., Hoppe, A., de la Riva, J., 2008. Doline probability map using logistic regression and GIS technology in the central Ebro Basin (Spain). Environmental Geology 54, 963977.

LCPC. 2002. Evaluation des aléas liés aux cavités souterraines. Guide technique. Juin 2002. LCPC Collection Environnement, 130 p.

LCPC. 2008. Les marnières de Haute-Normandie. Méthodologies d'étude et de prévention. Guide technique. Septembre 2008. LCPC Collection Environnement, 112 p.

Mancini, F., Stecchi, F., Gabbianelli, G., 2009. GIS-based assessment of risk due to salt mining activities at Tuzla (Bosnia and Herzegovina). Engineering Geology 109 (3-4), 170-182. 
Mardhel, V., Gravier, A., Koch-Mathian, J.Y., 2006. Cartographie de la vulnérabilité simplifiée des eaux souterraines du bassin Seine-Normandie et application aux sites BASOL. Darcy 2006 International Symposium - Aquifer Systems Management.

Marie S., Barchi P., Caous J.Y., Schomburck S., Vinchon C., 2004. Cartographie préliminaire de l'aléa "mouvements de terrain liés à la présence de cavités souterraines, suite à de fortes pluviosités". Arrondissement de Cambrai (Nord). BRGM/RP-52959-FR, 73 p, 36 ill., 1 app., 1 CDROM, 1 pl.

MATE (Ministere de l'Aménagement du Territoire et de l'Environnement), 1999. Plans de prévention des risques naturels (PPR) - Risques de mouvements de terrains. Guide méthodologique. La Documentation Francaise, Paris.

Merad, M., Verdel, T., Roy, B., Kouniali, S., 2004. Use of multi-criteria decision-aids for risk zoning and management of large areas subjected to mining-induced hazards. Tunnelling and Underground Space Technology 19 (2), 125-138.

Neuhäuser, B., Terhorst, B., 2007. Landslide susceptibility assessment using "weights-of-evidence" applied to a study area at the Jurassic escarpment (SW-Germany). Geomorphology 86 (1-2), 12-24.

Poitout, M.J., Piraud, J., 2003. Origine et traitement des fontis survenus sur le plateau picard le long de 1 LGV Nord. Après-mines 2003, 5-7 February 2003, Nancy.

Rezaei Moghaddam, M.H., Khayyam, M., Ahmadi, M., Farajzadeh, M., 2007. Mapping susceptibility landslide by using the weight-of-evidence model: a case study in Merek Valley, Iran. Journal of Applied Science, 7 (22), 3342-3355.

Ross, T.J., 1995. Fuzzy Logic with Engineering Applications. McGraw-Hill, New York.

Saboya, F. Jr., Alves, M. da G., Pinto, W.D., 2006. Assessment of failure susceptibility of soil slopes using fuzzy logic. Engineering Geology 86 (4), 211-224.

Sánchez, M.A., Foyo, A., Tomillo, C., Iriarte, E., 2007. Geological risk assessment of the area surrounding Altamira Cave: A proposed Natural Risk Index and Safety Factor for protection of prehistoric caves. Engineering Geology 94 (3-4), 180-200.

Soriano, M.A., Simón, J.L.,1995. Alluvial dolines in the central Ebro basin, Spain: a spatial and developmental hazard analysis. Geomorphology 11 (4), 295-309.

Thierry, P., Prunier-Leparmentier, A.M., Lembezat, C., Vanoudheusden, E., Vernoux, J.F., 2009. 3D geological modelling at urban scale and mapping of ground movement susceptibility from gypsum dissolution: the Paris example (France). Engineering Geology 105 (1-2), 51-64.

Upchurch, S.B., Littlefield, J.R., 1988. Evaluation of data for sinkhole-development risk models. Environ. Geol. 12, 135-140.

Van Den Eeckhaut, M., Poesen, J., Dusar, M., Martens, V., Duchateau, Ph., 2007. Sinkhole formation above underground limestone quarries: A case study in South Limburg (Belgium). Geomorphology 91 (12), 19-37. 
Waltham, T., Bell, F., Culshaw, M., 2005. Sinkholes and Subsidence: Karst and Cavernous Rocks in Engineering and Construction. Springer, Praxis , 382 pp.

White, W.B., 1988. Geomorphology and hydrology of karst terrains. Oxford Univ. Press, 464 p.

Yilmaz, I., 2007. GIS based susceptibility mapping of karst depression in gypsum: A case study from Sivas basin (Turkey). Engineering Geology 90 (1-2), 89-103.

Zadeh, L.A., 1965. "Fuzzy Sets”. Information and Control 8, 338-353.

Zhou, W., Beck, B.F., Adams, A.L., 2003. Application of matrix analysis in delineating sinkhole risk areas along highway (I-70 near Frederick, Maryland). Environmental Geology 44, 834-842. 


\section{TABLE CAPTION}

Table 1 Controlling factors for the Arras site.

\begin{tabular}{|c|c|c|c|c|c|}
\hline & $\begin{array}{l}\text { Chalkpit } \\
\text { s }(+ \\
\text { refuge- } \\
\text { cavities) }\end{array}$ & $\begin{array}{l}\text { Military } \\
\text { sap }\end{array}$ & Controlling Factors & Nature & $\begin{array}{l}\text { Cartographic } \\
\text { support }\end{array}$ \\
\hline \multirow{3}{*}{$\begin{array}{l}\text { Presence } \\
\text { susceptibility } \\
\text { (PS) }\end{array}$} & $X$ & & $\begin{array}{l}\text { Geological: nature of the } \\
\text { substratum formations }\end{array}$ & qualitative & Geological map \\
\hline & & $X$ & $\begin{array}{l}\text { Historical: Location of } \\
\text { the front lines }\end{array}$ & qualitative & Military maps \\
\hline & $\mathrm{X}$ & & $\begin{array}{l}\text { Historical: proximity to } \\
\text { historical centres of each } \\
\text { Artois village }\end{array}$ & quantitative & $\begin{array}{l}\text { Map with church } \\
\text { locations }\end{array}$ \\
\hline \multirow{4}{*}{$\begin{array}{l}\text { Rupture } \\
\text { susceptibility } \\
\text { (RS) }\end{array}$} & $X$ & & $\begin{array}{l}\text { Depth: overburden } \\
\text { thickness }\end{array}$ & quantitative & $\begin{array}{l}\text { Overbuden } \\
\text { isopach }\end{array}$ \\
\hline & $X$ & & $\begin{array}{l}\text { Geological: nature of the } \\
\text { overburden formations } \\
\text { (permanent factor) }\end{array}$ & qualitative & Geological map \\
\hline & $X$ & $\mathrm{X}$ & $\begin{array}{l}\text { Hydrology: surface water } \\
\text { infiltration } \\
\text { (triggering factor) }\end{array}$ & qualitative & $\begin{array}{l}\text { Network } \\
\text { persistence and } \\
\text { development } \\
\text { map (named } \\
\text { IDPR) }\end{array}$ \\
\hline & & $\mathrm{X}$ & $\begin{array}{l}\text { Hydrogeology: water } \\
\text { table level rise rise } \\
\text { (triggering factor) }\end{array}$ & quantitative & $\begin{array}{l}\text { Very high water } \\
\text { piezometric level } \\
\text { of } 2001\end{array}$ \\
\hline
\end{tabular}




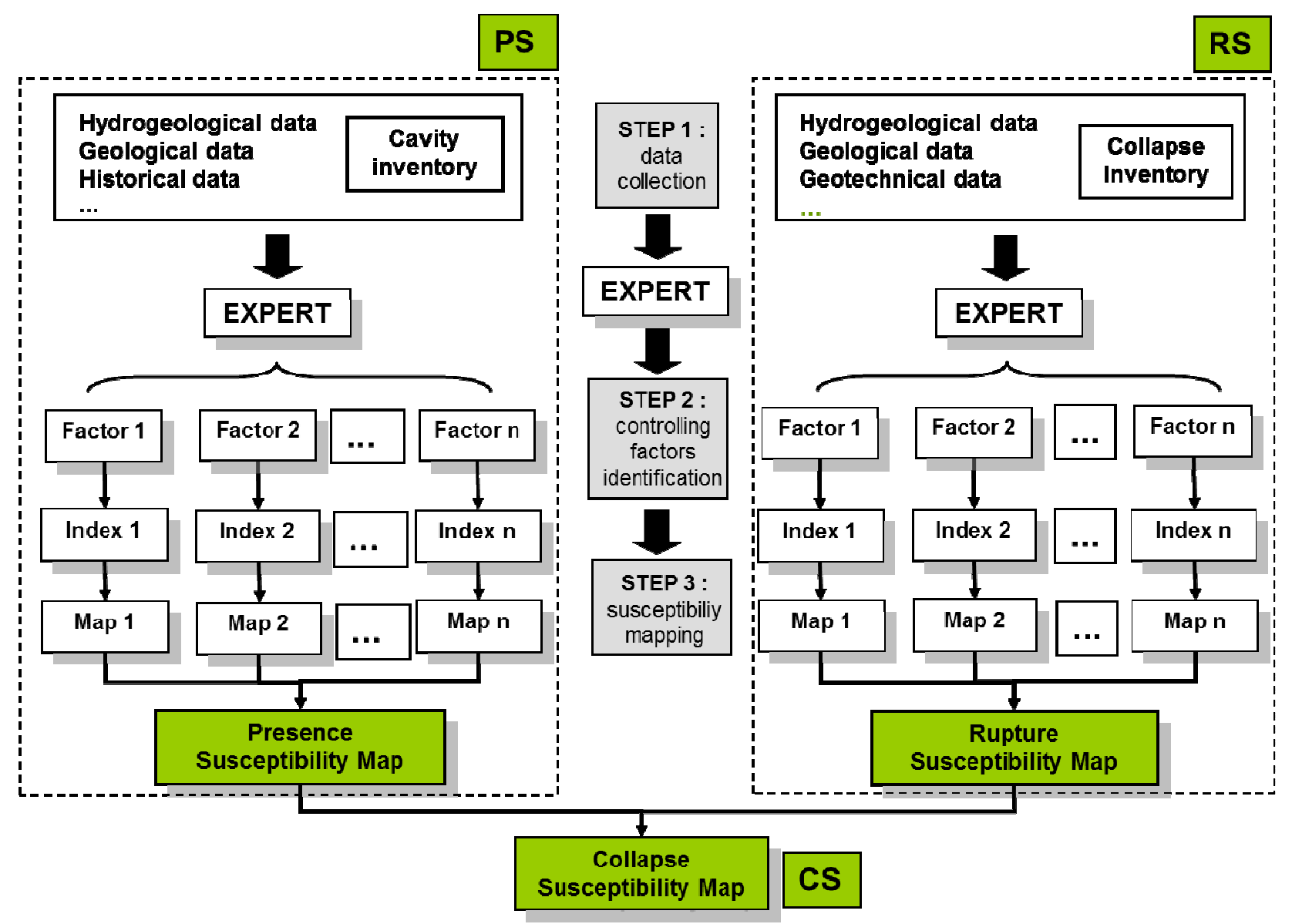

Fig. 1. Flowchart for assessing collapse susceptibility of abandoned underground structures. 
A)

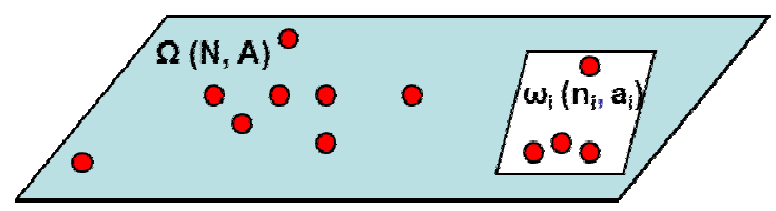

B)

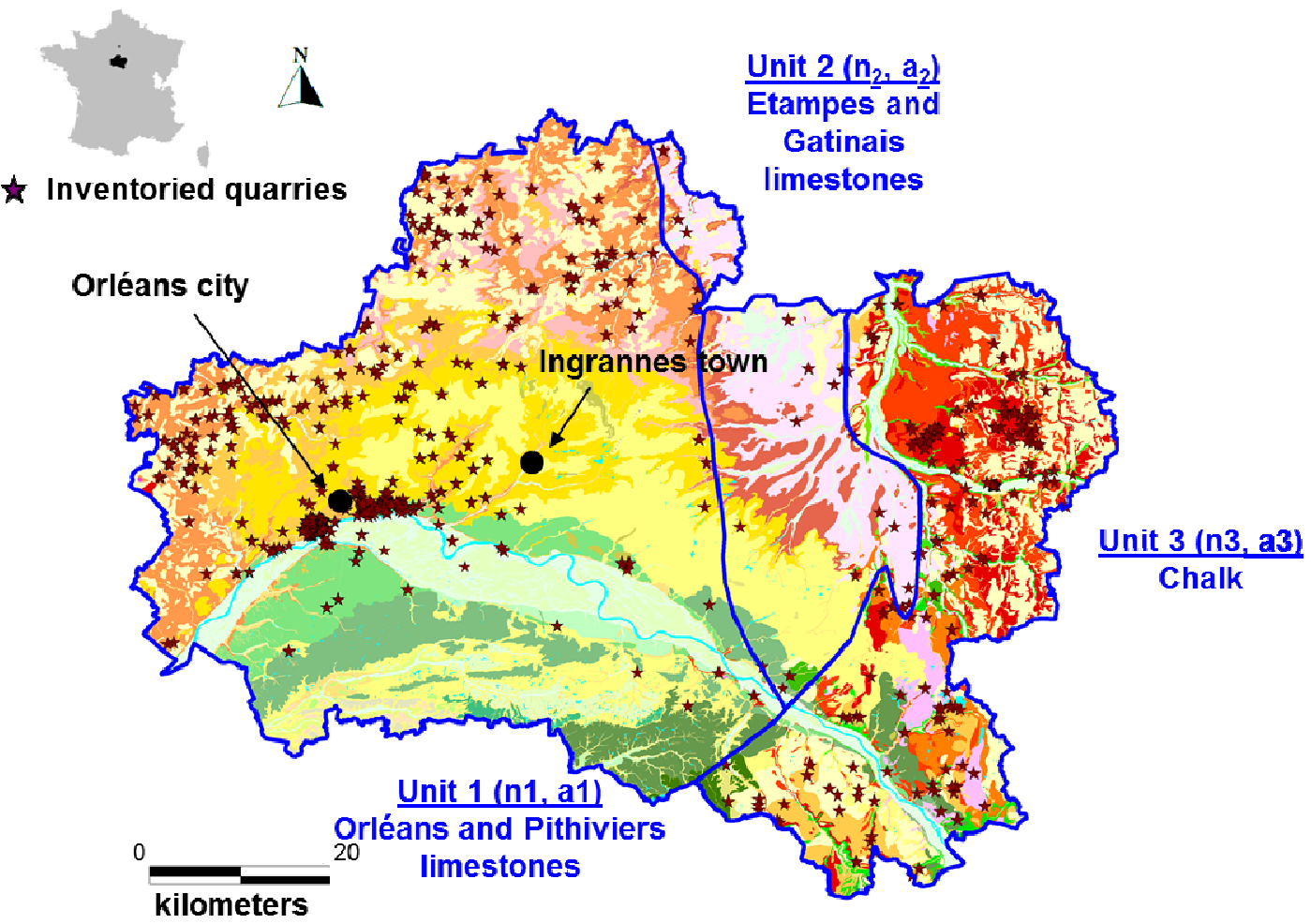

Fig. 2. Generic example of the application of the modified "weight of evidence" to take into account qualitative criteria. 2A: theoretical spatial units; 2B: spatial units applied to a geological criterion controlling the presence of quarries in the Loiret Department of France.
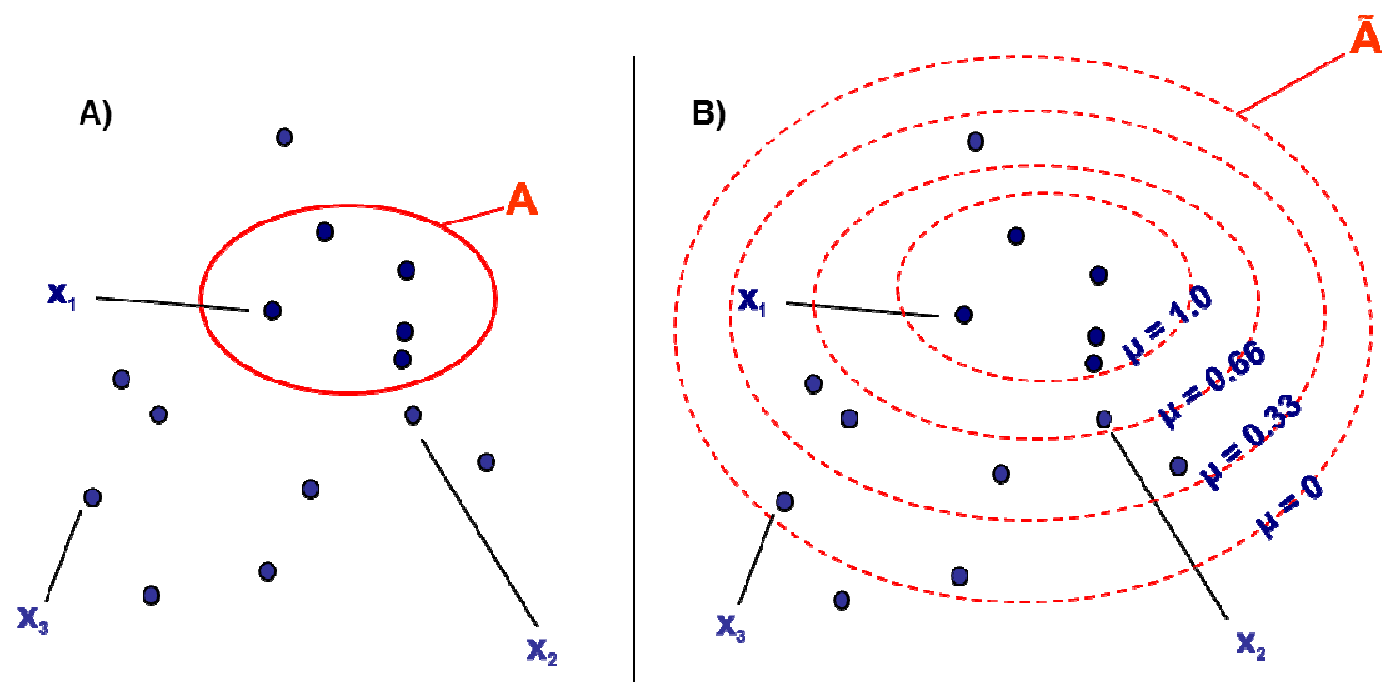

Fig. 3. Graphical representation of the set $A$ : A) under the classical Boolean theory; B) under the fuzzy set theory. 
A)

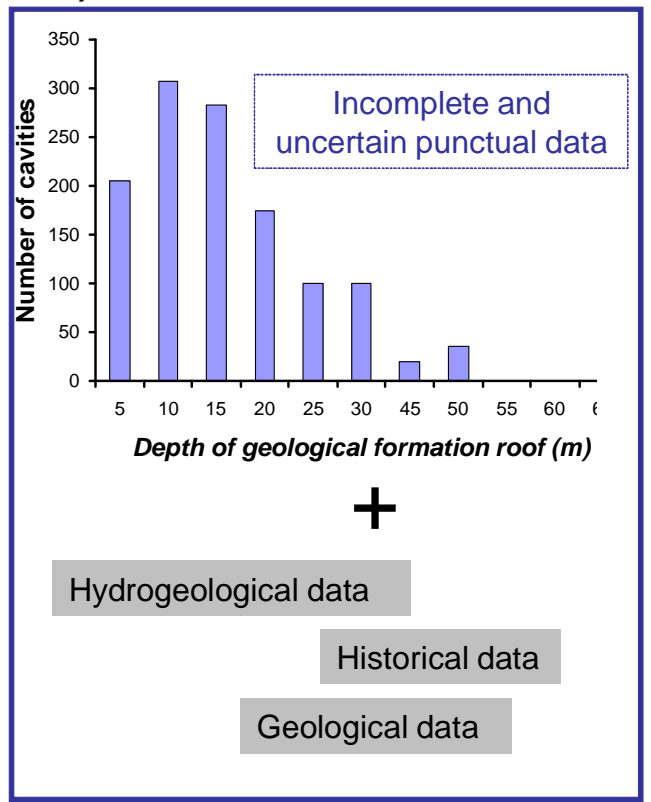

B)

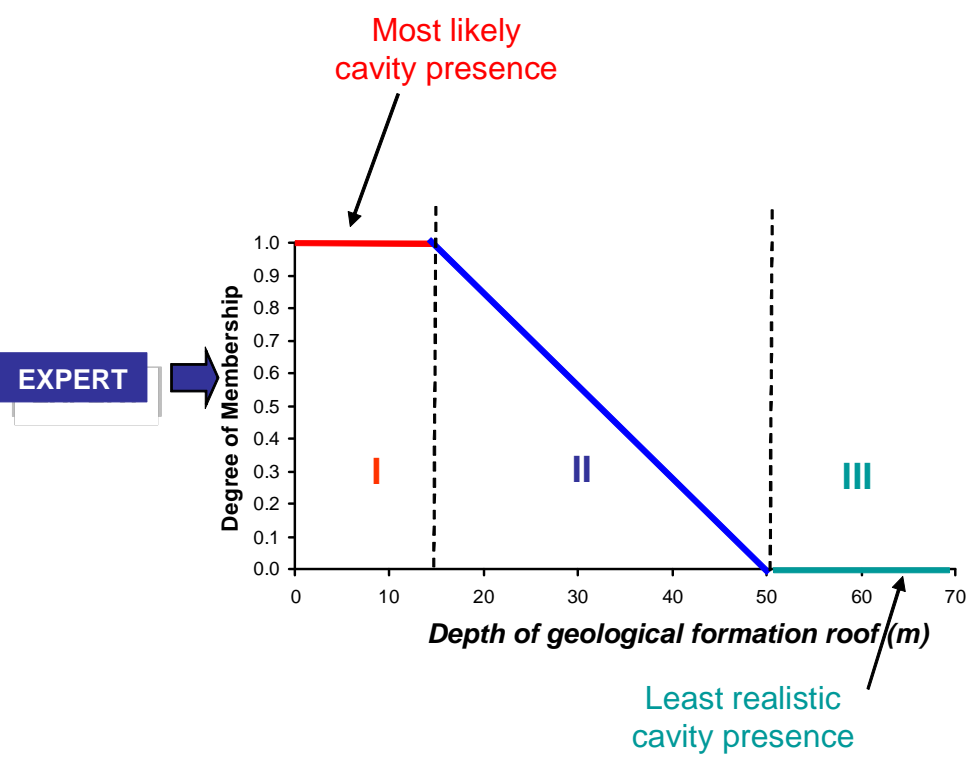

Fig. 4. Method of constructing the membership function relative to quantitative criteria: depth of the exploited geological formation.

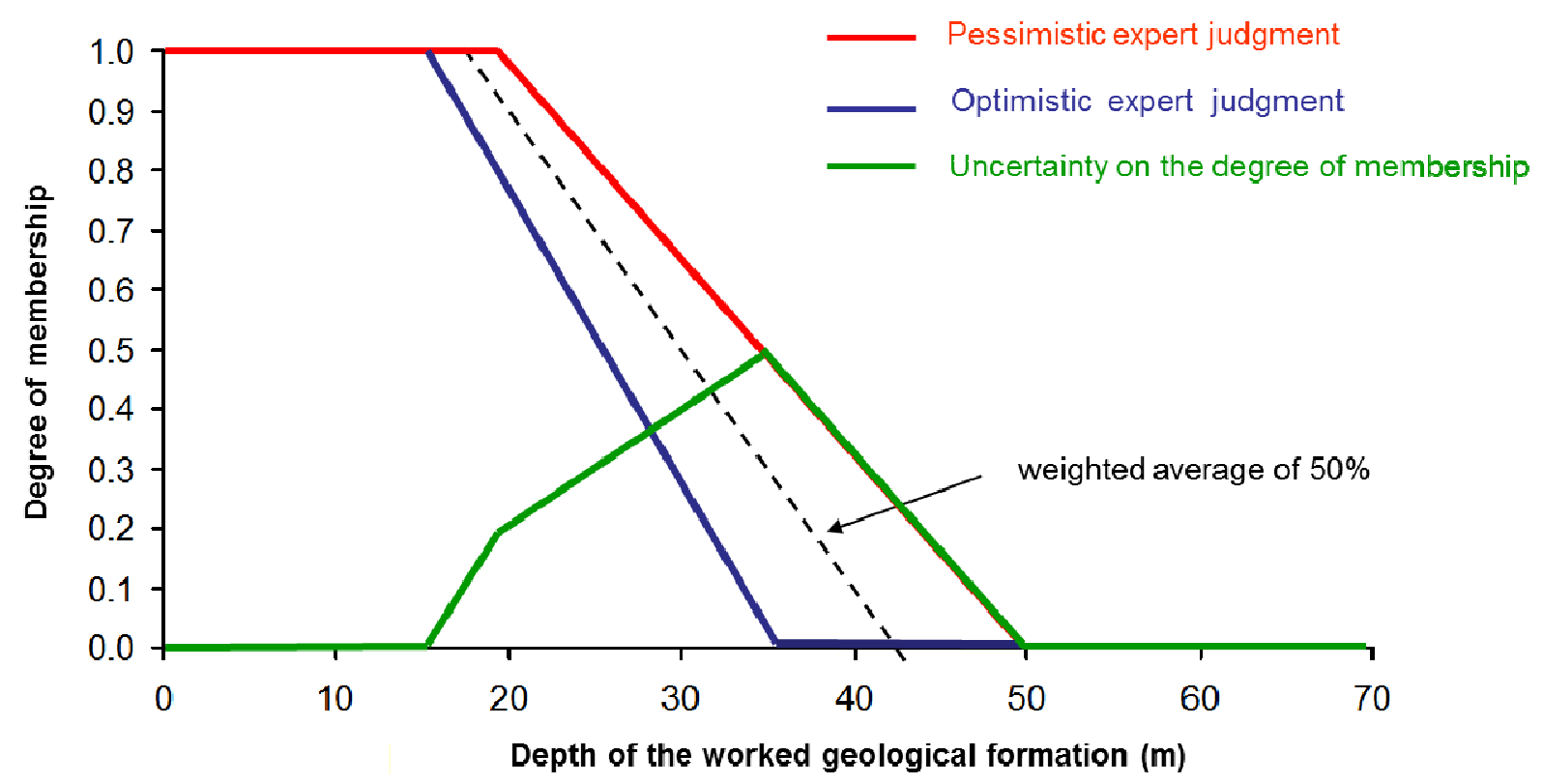

Fig. 5. Definition of a pair of optimistic and pessimistic scenarios to deal with the subjectivity in the assessment of the threshold levels. The green curve represents the value of uncertainty on the degree of membership. 


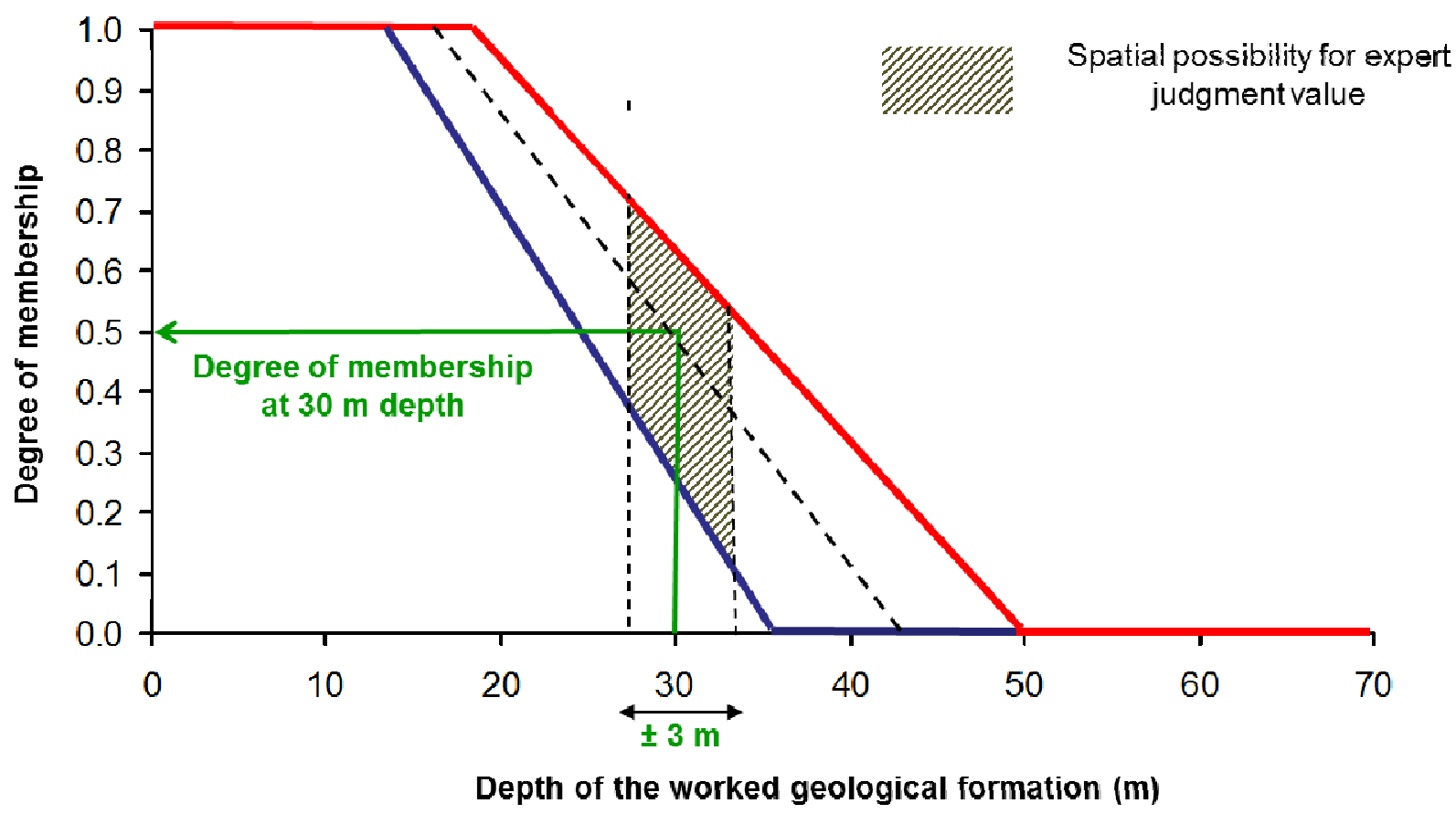

Fig. 6. Definition of the global uncertainty integrating cartographic input data and expert choice uncertainty.

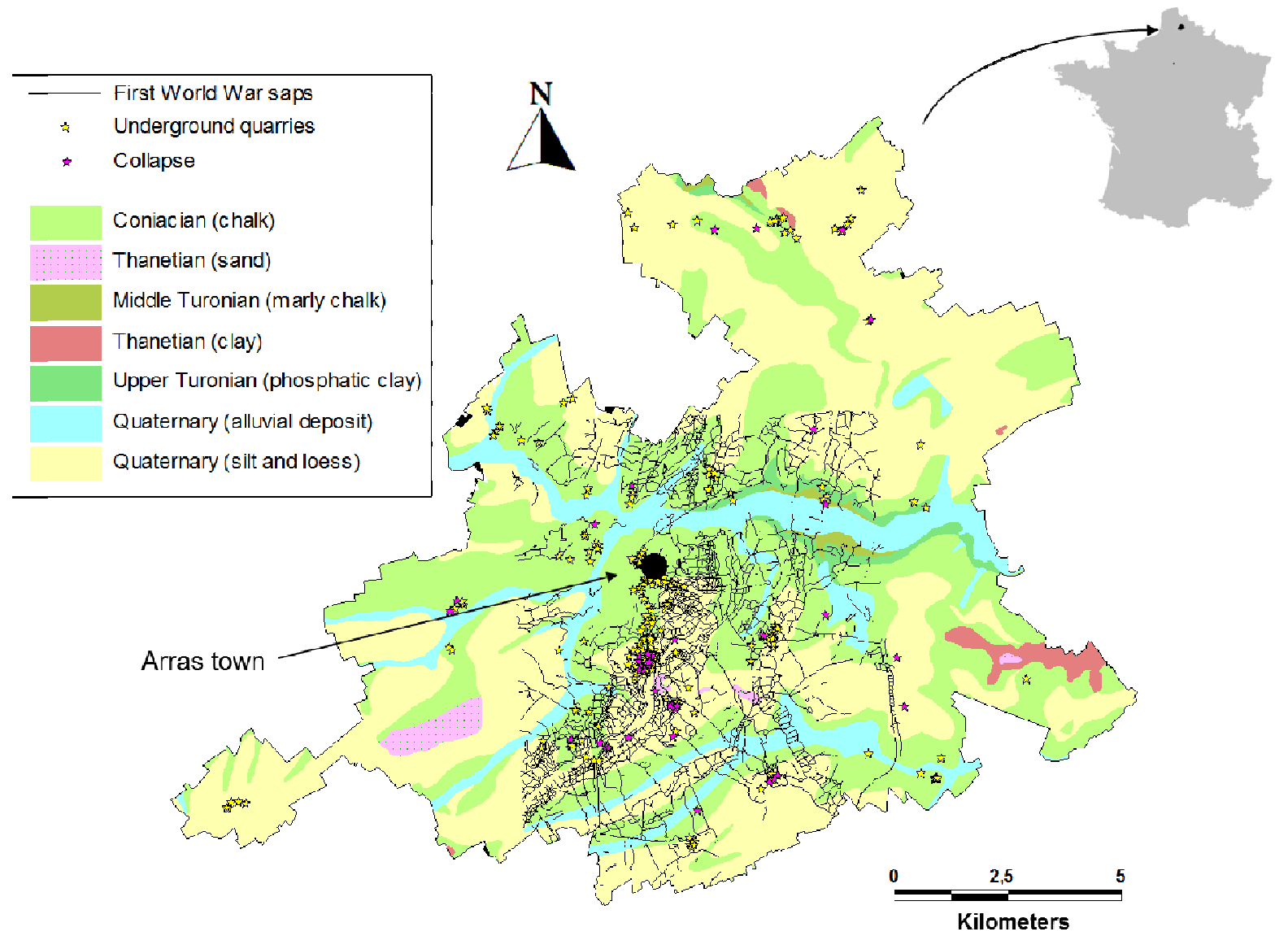

Fig. 7. Geological map at a 1/50 000 scale of the Arras region and the cavities inventoried. 


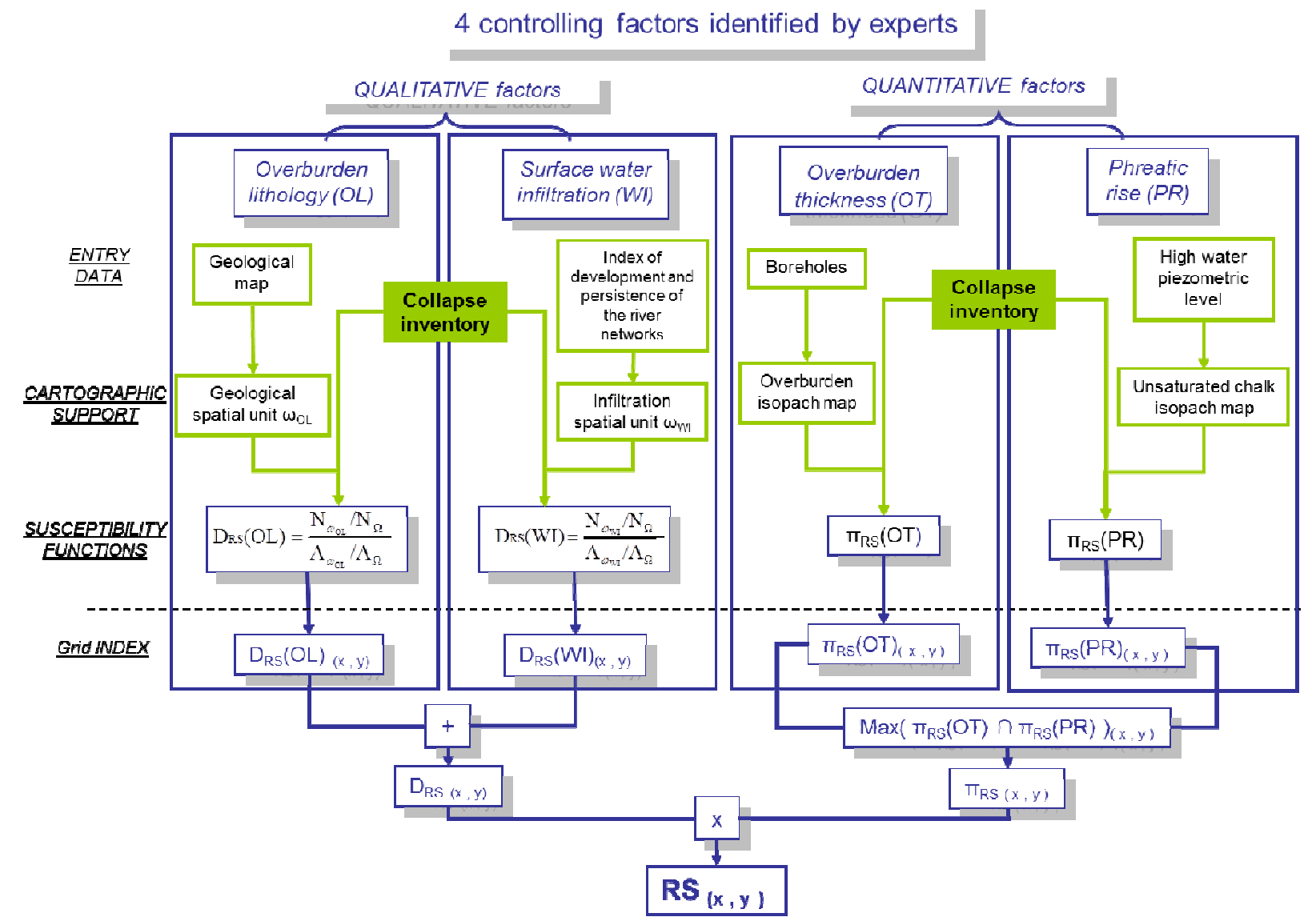

Fig. 8. Mathematical aggregation operations for calculating the rupture susceptibility index (RS). Example of the chalkpits, in the Arras region. 

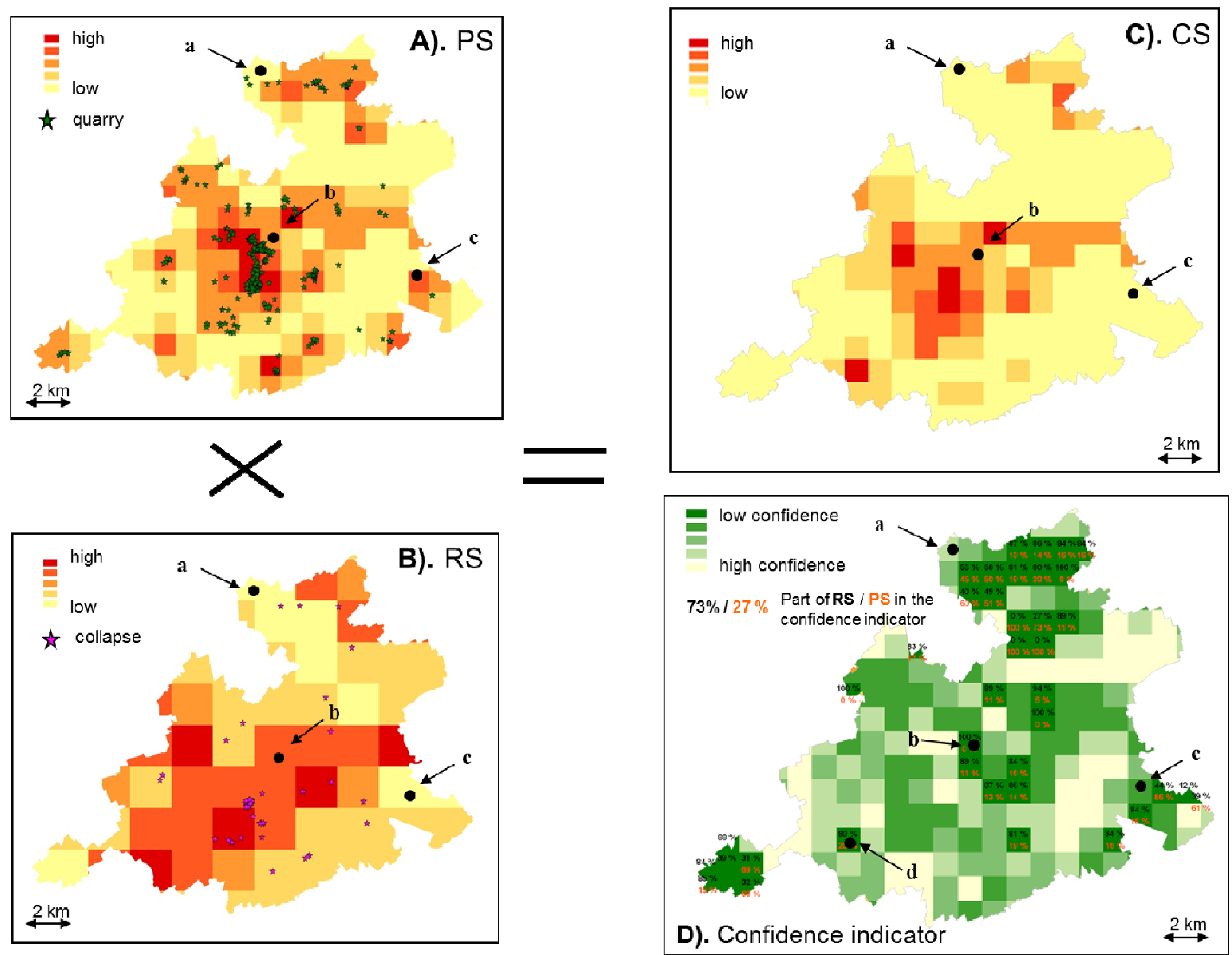

Fig. 9. Combination of the susceptibility of presence PS (Fig. 9A) of cavities and of the rupture susceptibility RS (Fig. 9B). The result constitutes the collapse susceptibility map of chalkpits in the Arras territory (Fig. 9C) combined with the mapping of confidence indicator. 